\title{
Applying Metaphor in Writing English Scientific Texts
}

\author{
Rusdi Noor Rosa \\ Faculty of Languages and Arts, \\ UniversitasNegeri Padang \\ Padang, Indonesia \\ rusdinoorrosa@yahoo.com
}

\author{
Rudy Sofyan \\ Faculty of Cultural Sciences, \\ University of Sumatera Utara \\ Medan, Indonesia \\ rudy@usu.ac.id \\ bahagiatarigan@yahoo.com
}

\author{
Bahagia Tarigan \\ Faculty of Cultural Sciences, \\ University of Sumatera Utara \\ Medan, Indonesia \\ rudy@usu.ac.id \\ bahagiatarigan@yahoo.com
}

\begin{abstract}
Most of English texts written by Indonesian students do not reflect the characteristics of English written text, even their texts resemble spoken texts conveyed through writing. A written text should be different from a spoken text for their different characteristics. The complexity of grammar in clause constructions of written texts may serve as the core distinguishing factor between the two kinds of texts. However, the question arises about how complex or how complicated the written text grammar is. This article is aimed at applying the concept of systemic functional linguistics-based metaphor (SFL-based metaphor) to distinguish a written text from a spoken text. In particular, this article applies the SFL-based metaphor concept in improving the dissertation proposal texts of the students. The application of the SFL-based metaphor concept is related to the lexical density of a clause through which a characteristic of a written text is generated. The realization of lexical density should give a credit to nominalization as a technique of reducing the number of clauses in a written text. Furthermore, a written text is closely related to a scientific text taking academicians including students, teachers, and lecturers as the readers. The data were 10 dissertation proposals written by the students of Linguistics Doctoral Program at the University of Sumtera Utara some of which are presented in this article to demonstrate the process of applying the SFL-based metaphor in improving the texts. Applying this concept is particularly helpful for those in the writing process of their final projects at universities.
\end{abstract}

Keywords_English written text; lexical density; nominalization; SFL-based metaphor

\section{INTRODUCTION}

Language facilitating the daily interaction of human being is delivered in either oral or written form. Oral language, also known as spoken language, is the language used in a variety of human social interactions dominating everyday use of written language. Spoken language is more widely used for the purpose of effective and efficient communication. The effectiveness as the measurement of successful communication is in different angle from the efficiency with its attention to the time consumption in communication. Meanwhile, written language is the language realization in scientific articles, books, newspapers, magazines, and other written media.

The problem arises when the spoken language is used in written texts, a common problem of people in the language with a poor classification of spoken and written language. English as a language with a strict distinctive classification of spoken and written language has some characteristics of written language in terms of incongruence, impersonality, lexical density, and more condensed clauses (see Halliday 1985, 1994; Martin 1985, 1992; Ravelli and Ellis 2004; Schleppegrell 2004; Schleppegrell and Colombi 2002).

Generally, a written text needs careful reading and written language ability in getting the message carried out through its condensed clauses. This implies that native speakers of a particular language also find it hard to understand written texts in their native language. However, this does not mean the unclear message in a written text because it does have a clear message as one of some other requirements in writing. In writing a written text, a writer has to be able to put several ideas in a single clause by avoiding the occurrence of run-ons clauses (Rosa 2008; 2012; 2013). The lack of written language knowledge and skills becomes one of the obstacles encountered by many writers, particularly Indonesian writers, to publish their articles in international journals. One of the factors leading to such problem is the unclear division between spoken and written language in bahasa Indonesia.

This paper talks about systemic functional linguistics-based metaphor (SFL-based metaphor) as a means to write a good English written text, particularly in writing a dissertation proposal. The use of metaphor is helpful to overcome the problem of insufficient knowledge and skills in a written language under the consideration of writing more condensed clauses through the application of nominalization.

The four characteristics - incongruence, impersonality, lexical density, and more condensed clauses - can be discussed under the topic of metaphor. Traditionally, the term metaphor is closely related to the literary world for its function as a comparison between two related objects (Black 1993; Cameron and Low 1999; Lakoff and Johnsen 1980). However, Halliday can see it from different point of view in which linguistics should also include it as a linguistic theory. According to Halliday (1994, p. 340), 
metaphor is a word used for something resembling that which it usually refers to. This definition seems similar to the traditional concept of metaphor as well-known proposed by Lakoff and Johnsen (1980). However, Halliday illustrates it by using a question "how is this meaning expressed?" not "how is this word used?". The use of metaphor can be seen in the clauses (1a-b).

(1) a. A large quantity of protests came in following the announcement.

b. A flood of protests poured in following the announcement.

The clause in (1a) demonstrates the common example of a common clause which Halliday says a "congruent" form. Meanwhile, the clause in (1b) demonstrates the use of metaphorical clauses in which the word "flood"e is uncommonly used as a modifier of the word "protestse as the word "quantity" does in (1a). However, the two words - flood and quantity - share similar meaning referring to the large amount of something. The use of this uncommon word instead of the common/normal one results in a metaphorical form. Furthermore, the clause in (1b) focuses on how the meaning is expressed, it does not pay attention to the words constituting the clause as long as they represent the same meaning. The difference of congruent form and metaphorical form is illustrated in Figure 1.

seen "from below"

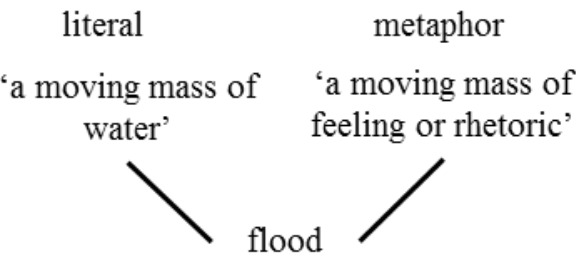

seen "from above"

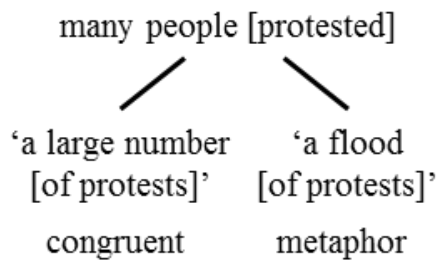

Fig. 1. Two perspectives on metaphor (Halliday 1994, p. 342)

The left side of Figure 1 shows that the word 'moving' followed by the word 'water' produces a congruent form as 'moving' is the natural characteristic of water. Meanwhile, the word 'moving' followed by the word 'feeling' produces a form of metaphor as 'mobile' is an activity performed by concrete objects, while the 'feeling' is a word with abstract meaning. Thus, the 'feeling' can be compared with anything that moves because feeling also experiences changes. The same case happened on the right side of Figure 1 where 'a large number' is metaphorized with 'a flood'. In other words, 'a large number' has a content sharing a similar meaning to 'flood' because flooding is water coming in large numbers.

The difference between congruence and metaphor also works in a clause level. A congruent clause is constructed by the elements playing their 'normal' grammatical function: nouns occupying nominal functions, verbs occupying verbal functions, and so forth. On the other hand, nouns occupying verbal functions or vice versa indicates a metaphorical form. Now, look at the clauses in $(2 \mathrm{a}-\mathrm{b})$.

(2) a. He doesn't attend the lecture because he is sick.

b. His absence from the lecture is caused by his illness.

Clause (2a), a complex clause, is a form of clauses that are congruent because it is a normal or usual form of a clause in which two ideas are presented separately in two clauses by using conjunction. While in clause (2b), the grammatical function of the constituents of the clause ( $2 \mathrm{a}$ ) is changed. The function of the verb group 'does not attend' is changed into a nominal function represented by the noun 'absence', the function of the conjunction 'because' is changed into a verbal function represented by the verb group 'is caused', and the function of the adjective 'sick' is changed into a nominal function represented by the noun 'illness'. The main difference between the two clauses lies on the different type of clauses possessed by (2a) and (2b). The clause in (2a) is a complex clause, while the clause in (2b) is a simple clause. The changing role of the grammatical function of the clauses constituents demonstrates the way of metaphor construction.

In line with the importance of having good skills in written language especially those related to writing scientific articles, it is necessary to do a research on applying an SFL-based metaphorin improving the quality of Indonesian writers' English scientific texts. This is a descriptive qualitative research using a content analysis as the research design. The data were 10 dissertation proposals in English written by the students of Linguistics Doctoral Program at the University of Sumatera Utara. The proposals were selected randomly submitted from 2014 to 2016. All of the clauses in the proposals were read to analyze whether they had corresponded to the criteria of an English written text. The analysis also included the improvement for the clauses unable to meet the criteria of English written text by applying the SFL-based metaphor. 


\section{DISCUSSION}

Based on the data analysis, it was found that most of the students' dissertation proposals did not meet the mentioned criteria of a good written text. Among the 10 students' dissertation proposals, Student C's proposal was the closest to meet the criteria; only did 30\% of his clauses need improvement. Meanwhile, the other students' proposals needed more than $50 \%$ of improvement. The findings related to the students' achievement of the criteria of a good written text are displayed in Figure 2.

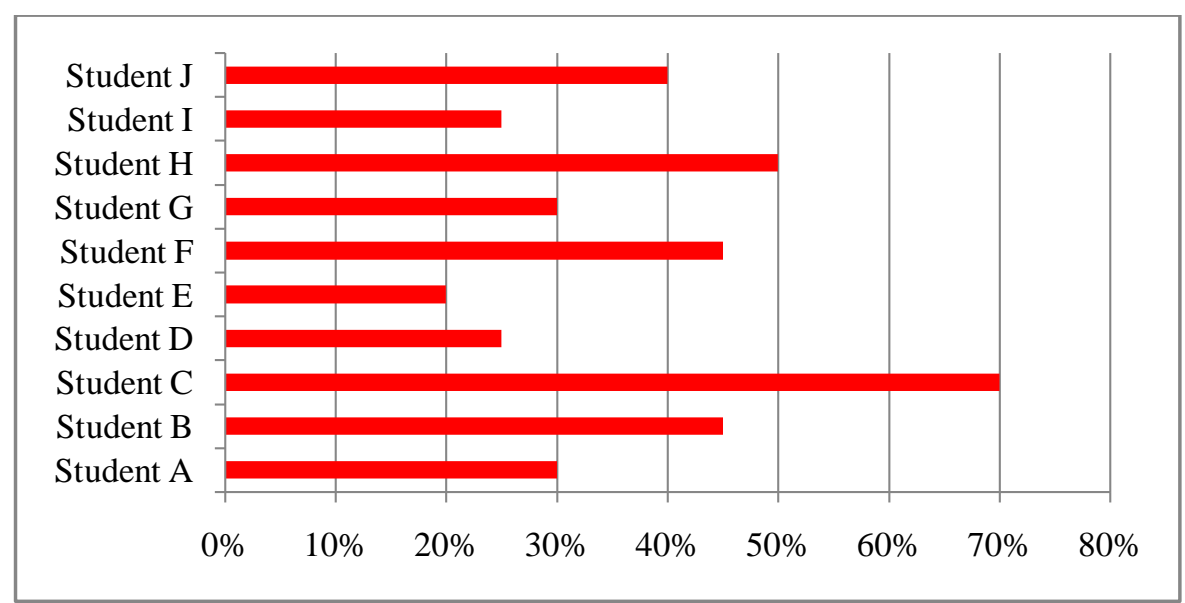

Fig. 2. The students' achievement of the criteria of a good English written text

One of the ways of constructing metaphorical clauses is through nominalization, a process of noun formation from groups, phrases, or clauses. Now, look at the clause in (3).

(3) They were selected as the research participants because they had 10 years of experience as professional translators although they were not familiar with the use of Translog.

A clause in (3) is an example of a grammatically accepted English clause complex; nevertheless, referring to the criteria of a good written text, itis a clause demonstrating the use of spoken language where the clause can be understood easily because that is how people commonly or normally speak, so the clause is congruent. The clause in (3) is a clause complex under the consideration that it is composed of 3 clauses: (i) The participants were selected; (ii) they had 10 years of experience as professional translators; and (iii) they were not familiar with the use of Translog. The small number of words used in each clause facilitates easy understanding of the meaning of the clauses. The clauses in (3) show hypotaxis relationship where the existence of clause (ii) depends on clause (i), and clause (iii) depends on clause (ii). In hypotaxis relation, Halliday uses symbols $(\alpha)$ for the primary clause, and symbol ( $\beta$ ) for the secondary clause. Furthermore, because the relationship between ( $\alpha$ ) and ( $\beta$ ) in (I) and (II) includes causal and concessive relationship, then the logical hypotaxis relationship is known as enhancement, symbolized by (x). The analysis of the clause complex in (3) can be seen in Figure 3.

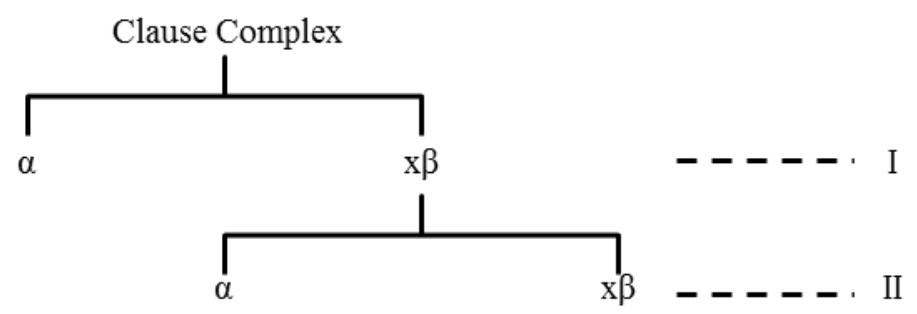

Fig. 3.Hypotaxis relationship of the clause complex in (3)

Figure 3 displays the logical relationship of enhancement between clause (i) and clause (ii) is ( $\alpha \times \beta)$, as clauses (ii) and (iii) do. The dotted lines on Figure 3 state the layer of the clause density in a clause complex, thus clause (3) has two layers. In a written language, the congruent form in (3) is changed into a metaphorical form through the process of nominalization modeled in Table 1.

TABLE 1 NOMINALIZATION OF CLAUSE IN (3)

\begin{tabular}{|c|l|l|}
\hline Clauses & \multicolumn{1}{|c|}{ Congruent } & \multicolumn{1}{|c|}{ Metaphorical (Nominalization) } \\
\hline Clause (i) & They were selected as the research participants & Their status as the research participant \\
\hline Clause (ii) & they had 10 years of experience as professional & their 10 years of experience as professional \\
\hline
\end{tabular}




\begin{tabular}{|c|l|l|}
\hline Clauses & \multicolumn{1}{|c|}{ Congruent } & \multicolumn{1}{c|}{ Metaphorical (Nominalization) } \\
\hline & translators & translators \\
\hline Clause (iii) & they were not familiar with the use of Translog & their unfamiliarity with the use of Translog \\
\hline
\end{tabular}

Now, the three clauses in (3), after having been nominalized, are rewritten in one clause as in (4).

(4) Their status as the research participants was caused by their 10 years of experience as professional translators despite their unfamiliarity with the use of Translog

In a scientific language, a clause has a formula which can also be used to construct other clauses with the same formula. So, the formula of how the clause in (4) is constructed is " $\mathrm{X}$ was caused by $\mathrm{Y}^{\mathrm{e}}$.

Clause (4) demonstrates an example of English written clause in which the clause is composed of many words despite its status as a single clause. The density of the clause constituents, according to Halliday (1985, p. 62), is called lexical density. Halliday proposed a model of lexical density measurement as in Figure 4.

$$
\text { Lexical Density }=\frac{\text { The Number of Lexical }}{\text { The Number of Clauses }}
$$

Fig. 4. Measuring lexical density

The lexical categories involved in the model in Figure 4 are nouns, verbs, adjectives, and adverbs. Other categories prepositions, conjunctions, articles - do not play a role in constructing the lexical density of a clause for their role as grammatical markers. By using the model in figure 3, the lexical density of clauses in (3) and (4) is presented in Table 2.

\begin{tabular}{|l|l|l|}
\hline \multicolumn{1}{|c|}{ TABLE 2 LEXICAL DENSITY OF CLAUSE IN (3) AND (4) } \\
\hline The number of clauses & 3 & Clause (4) \\
\hline The number of lexical items & 18 & 1 \\
\hline Lexical density & $18 / 3=6$ & 15 \\
\hline
\end{tabular}

Based on the analysis displayed in Table 2, the clause in (3) has a larger number of clauses than the clause in (4); each clause in (3) contains only 6 lexical items on average, while the clause in (4) contains 15 lexical items demonstrating a lexically dense clause. Thus, it is clear that the clause in (3) is a clause commonly used in a spoken text indicated by less number of lexical items, while the clause in (4) is typically used in a written text. In other words, the use of metaphor realized through the nominalization process can change the form of spoken language into written language.

The density of lexical items in a clause as a characteristic of language used in written texts is not only able to change three clauses into a single clause; but it is also able to change more than three clauses into a single clause. The clause complex in (5) is composed of a lot of number of clauses.

(5) The SL elements that exist in the TT often become violation against the TL system, and make the TT discordant and strange to the TL readers because the ST elements that present particularity in the SL are fully transferred into the TT.

The clause in (5) has five clauses as shown in (6).

(6) (i) The SL elements that exist in the TT

(ii) the SL elements often become violation against the TL system

(iii) make the TT discordant and strange to the TL readers

(iv) the ST elements present particularity in the SL

(v) the ST elements are fully transferred into the TT

The clause in (5) divided into five clauses as in (6) reveals the characteristic of clauses used in a spoken text in which a clause complex contains a large number of clauses with a small number of lexical items. Besides, the clause in (5) also shows how people commonly speak to make their ideas easily caught by the listener. The clause complex in (5) can be changed into a sing le clause by using metaphorical form through nominalization as shown in Table 3. 
TABle 3 Nominalization of Clause in (5)

\begin{tabular}{|c|c|c|}
\hline Clauses & Congruent & Metaphorical (Nominalization) \\
\hline Clause (i) & The SL elements that exist in the TT & The presence of the SL elements in the TT \\
\hline Clause (ii) & $\begin{array}{l}\text { the SL elements often become violation against } \\
\text { the TL system }\end{array}$ & the violation against the TL system \\
\hline Clause (iii) & $\begin{array}{l}\text { make the TT discordant and strange to the TL } \\
\text { readers }\end{array}$ & $\begin{array}{l}\text { the } \mathrm{TT} \text { discordant and strange to the } \mathrm{TL} \\
\text { readers }\end{array}$ \\
\hline Clause (iv) & the ST elements present particularity in the SL & the SL particularity in the ST elements \\
\hline Clause (v) & $\begin{array}{l}\text { the ST elements are fully transferred into the } \\
\text { TT }\end{array}$ & $\begin{array}{l}\text { the complete transfer of the ST elements into } \\
\text { the TT }\end{array}$ \\
\hline
\end{tabular}

The metaphorical forms through nominalization in Table 3 change the clauses into noun phrases without eliminating any single message found in its congruent form. The next step is by arranging the noun phrases into a single clause with high lexical density as seen in (7).

(7) The presence of the SL elements in the TT as the violation against the TL system results in the discordant and strange TT to the TL readers due to the complete transfer of the SL particularity in the ST elements into the TT.

The clause in (7) characterizes itself as a language used in a written text in which a single clause contains a large number of lexical items. Applying the model of lexical density, the lexical density in clause (7) is 20, while the clause in (5) has five clauses each composed, on average, of 5 lexical items. So, the formula of how the clause in (7) is constructed is " $\mathrm{X}$ results in $\mathrm{Y}^{\mathrm{e}}$.

Reducing the number of clauses in a clause complex is not an easy task to do without a good knowledge of nominalization and a lot of practice on it. Based on several data being analyzed and elaborated above, it is concluded that the steps of nominalization process illustrated in (8):

(8) (i) Identify the clauses used in a clause complex.

(ii) Separate the clauses, it will be much better to number the clauses.

(iii) Change each of the clauses into nominal phrases.

(iv) Pay more attention to the verbs as they are the core of the clauses on which the number of clauses depends.

(v) Analyze the relationship among the clauses to find out the best process to connect the nominal groups.

(vi) Arrange the phrases that have been nominalized into a complete sentence.

(vi) Read the sentence and give correction whenever necessary.

Having known these steps completely, forming metaphor through nominalization is not a difficult task. Having the ability in nominalization helps to write a good written text. Clauses (9a-b) below demonstrate the other improvement that has been done to the clauses of the students' proposal.

(9) a. While checking my students ${ }^{\text {ee }}$ translation assignment, I come across the reality that some students submit a very good result of translated version while others do not, even both works are acceptable. The idea then becomes stronger when I read many product-oriented research findings stating that translation product proved to be very low readability and accuracy but highly acceptable.

b. Checking the students ${ }^{\text {ee }}$ translation assignment reveals the reality of difference between the quality of the acceptable students $^{\text {ee }}$ works strengthened by the reading experience on weird product-oriented research findings about the very low readability of translation product with high acceptability.

The clause complex in (9a), composed of 8 clauses, is metaphorized into a single clause in (9b). This shows a very high level of lexical density found in (9b) which is also claimed to be a clause of a written text. The process of reducing the number of clauses in (9a) is shown in Figure 5. 


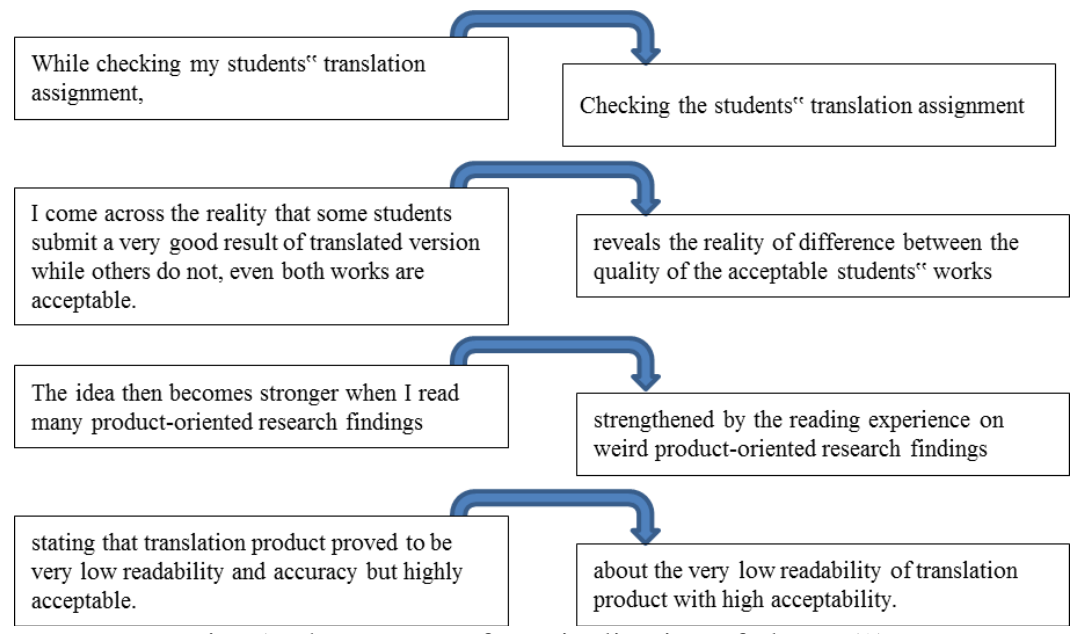

Fig. 5. The process of nominalization of clause (9)

Figure 5 provides the insight about what to do in the process of changing a less scientific text into an acceptable written text showing the characteristics of a scientific text.

\section{CONCLUSION AND RECOMMENDATION}

A written text is a text composed of clauses formed by using written language. The main characteristic of a written text is the high level of lexical density and the use of more condensed clauses. Metaphor through nominalization can be used as a means to facilitate the process of writing a good written text, particularly in writing a dissertation proposal. The denser the clause is the closer it is to a good written text.

The findings of this research recommend an SFL-based metaphor through a nominalization process as the best way of writing a good English scientific text. This recommendation implies a suggestion of reading a lot of English scientific texts and doing a lot of practice on nominalization process.

\section{References}

Black, M. (1993). More about metaphor.In Ortony, A. (Ed.), Metaphor and Thought.Second Edition. Cambridge: Cambridge University Press, 19-41.

Cameron, L. \& Low, G. (Eds).(1999). Researching and Applying Metaphor.Cambridge: Cambridge University Press.

Halliday, M.A.K. (1985). Spoken and Written Language. Oxford: Oxford University Press.

(1994), An Introduction to Functional Grammar. Second Edition. London: Arnold.

Lakoff, G. \& Johnson, M. (1980).Metaphors we live by. Chicago: University of Chicago Press.

Martin, J. R. (1985). Factual writing: Exploring and challenging social reality. Geelong. Victoria: Deakin University Press.

Martin, J. R. (1992). English text: System and structure. Philadelphia, PA: John Benjamins.

Ravelli, L. \& Ellis, R. (Eds.).(2004). Analyzing academic writing: Contextualized frameworks. London: Continuum.

Rosa, R. N. (2008). Thematic Progression as a Means to Keep Cohesion in Exposition Text.JurnalBahasadanSeni, 08(02): 1-9.

Rosa, R. N. (2012). PolaGerakTemapadaTulisanMahasiswa Tingkat III JurusanBahasadanSastraInggris UNP: AnalisistentangKepaduanTeks. JurnalBahasadanSeni. Vol. 12(02), pp. 169-183.

Rosa, R. N. (2013). Thematic Progression as a Model Used to Keep Cohesion in Writing an Exposition Text. Presented at Seminar on English and Language Teaching (SELT), 30 - 31 of Agustus 2013, Padang, 220-228.

Schleppegrell, M. J. (2004). The language of schooling. Mahwah, NJ: Lawrence Erlbaum.

Schleppegrell, M. J. and Colombi, M. C. (Eds.).(2002). Developing advanced literacy in first and second languages. Mahwah, NJ: Lawrence Erlbaum. 